\title{
Relation between Age-Related Macular Degeneration and Cardiovascular Events and Mortality: A Systematic Review and Meta-Analysis
}

\author{
Jie Wang, Yangjing Xue, Saroj Thapa, Luping Wang, Jifei Tang, and Kangting Ji \\ Department of Cardiology, The Second Affiliated Hospital and Yuying Children's Hospital, Wenzhou Medical University, \\ Xueyuanxi Road, No. 109, Wenzhou, Zhejiang 325000, China
}

Correspondence should be addressed to Kangting Ji; jikingt@163.com

Received 20 May 2016; Revised 27 September 2016; Accepted 14 November 2016

Academic Editor: Gui-shuang Ying

Copyright (C) 2016 Jie Wang et al. This is an open access article distributed under the Creative Commons Attribution License, which permits unrestricted use, distribution, and reproduction in any medium, provided the original work is properly cited.

\begin{abstract}
Data on the association between age-related macular degeneration (AMD) and cardiovascular disease and mortality are conflicting. The purpose of this report is to conduct a systematic review to better understand the role of AMD as a risk factor for CVD events and mortality. We searched Medline (Ovid) and Embase (Ovid) for trials published from 1980 to 2015. We included 20 cohort studies that reported relative risks with 95\% confidence intervals for the association of AMD and cardiovascular events and mortality, involving $29,964,334$ participants. In a random-effects model, the adjusted RR (95\% confidence interval [CI]) associated with AMD was 1.08 (1.00-1.117) for all-cause mortality (8 studies) and $1.18(0.98-1.43)$ for cardiovascular disease mortality (5 studies). The pooled RR (95\% CI) was 1.17 (0.94-1.45) for coronary heart disease (CHD; 3 studies) and $1.13(0.93-1.36)$ for stroke (8 studies). Findings from this systematic review support that AMD is associated with increased risk of all-cause mortality. The evidence that AMD predicts incident CVD events or CVD mortality remains inclusive and warrants further study in the future.
\end{abstract}

\section{Introduction}

Age-related macular degeneration (AMD) is a major cause of irreversible vision loss among elderly people in the developed world $[1,2]$. AMD has both early and late stages. It is affected by the dysfunction of a specialized cell layer in the back of the eye called the retinal pigmented epithelium (RPE). The macula has a high density of photoreceptors and provides detailed central vision [3]. The common features of early AMD include the presence of drusen and pigmentary abnormalities in the RPE; and late AMD is manifested through geographic atrophy or the development of neovascularization $[3,4]$.

Although the precise etiology of AMD remains unknown, the current evidence suggests that there are multiple similarities in the pathogenic mechanisms of both AMD and cardiovascular disease (CVD). AMD and CVD may connote shared underlying pathophysiological factors (e.g., advancing age, smoking, obesity, C-reactive protein, Apo lipoprotein E gene, and complement factor $\mathrm{H})[3,5]$. But epidemiological studies have not found a consistent association of AMD and CVD [6-9], although a previous systematic review [10] including 13 population-based studies concluded that there is an association between AMD and CVD risk and suggested that AMD is predictive of a small increase in risk of future CVD. Thirteen cohort studies with a total of 1,593,390 participants with 155,500 CVD events (92,039: stroke and 62,737: CHD) were included in previous systematic review. However, the systematic review omitted several important papers. Furthermore, 5 of the 13 cohort studies included in that review used a retrospective design. In addition, this review did not investigate the link between AMD and risk of mortality. Therefore, we conducted a systematic review to better understand the role of AMD as a risk factor for CVD events and mortality.

\section{Methods}

2.1. Data Sources and Search Strategy. Preferred Reporting Items for Systematic Review and Meta-Analyses (PRISMA) statement was followed [11]. We first searched the literature in April 2014 of the Medline (Ovid) and Embase (Ovid) using 
the following search terms: "retina macula degeneration", "retinal degeneration", "Age-related macular degeneration", "Cardiovascular Disease", "coronary heart disease", "heart failure", and so on. To make sure our study was based on up-to-date results, we further updated the literature search of the Cochrane Library, Medline, and Embase on November 11, 2015. Besides that, additional studies were identified through the reference lists of relevant reports.

2.2. Study Selection and Data Extraction. Two investigators (Y. W and Y. J. X) independently screened the titles or abstracts, or both, of the search results and assessed the remaining full-text articles for eligibility. Any uncertainty regarding eligibility was resolved by discussion. Studies were eligible for our systematic review if (1) the exposure of interest was AMD; (2) the outcome of interest was cardiovascular events (coronary heart disease (CHD), myocardial infarction (MI), heart failure, stroke, or cardiovascular disease mortality) or all-cause mortality; and (3) the study was a populationbased cohort study (i.e., not meeting abstracts or review articles). In the case of multiple publications from one study, we chose the articles with the largest sample or the longest follow-up interval.

Two investigators extracted the following data using standardized data extraction form: name of first author and year of publication; country cohort details and the number of participants; characteristic of the study population; mean follow-up years; assessment of exposure and outcome; type of CVD outcome; and covariate adjustment.

2.3. Data Analysis. We used the relative risk (RR) as the common measure of association across studies, and the hazard ratio (HR) or odds ratio (OR) was considered equivalent to the $\mathrm{RR}$, while the OR was converted into RR by the formula $\mathrm{RR}=\mathrm{OR} /[(1-\mathrm{Po})+(\mathrm{Po} \times \mathrm{OR})]$, in which Po is the incidence of the outcome of interest in the nonexplosive group. Forest plots were produced to visually assess the RR and corresponding 95\% confidence interval (CI) across studies [12]. The presence of heterogeneity across studies was evaluated by $Q$ statistic (significance level of $P<0.10$ ) and $I^{2}$ statistic (ranges from $0 \%$ to $100 \%$ with lower values representing less heterogeneity) [13]. The RRs were pooled using the DerSimonian and Laird inverse-variance-weighted randomeffects models. What is more, we investigated the influence of a single study on the overall risk estimates by omitting any of the studies in each turn. We also conducted subgroup analyses stratified by number of participants $(<10000$ versus $\geq 10000$ ), length of follow-up ( $<5$ versus $\geq 5$ ), type, and study design at baseline to assess the impacts of these variables on outcomes.

Analyses were performed with RevMan (version 5.2 for Windows; the Nordic Cochrane Centre, Copenhagen, Denmark). All statistical tests were 2 -sided and $\alpha<0.05$ was considered statistically significant level.

\section{Results}

3.1. Literature Search. The search strategy resulted in 4,156 unique citations (Figure 3). Of these, we included 27 articles after review of the title or abstract. After detailed examination, 7 literatures were excluded (reasons shown in Figure 3). In total, 20 articles [6-9, 14-29] were included, and the full list of publications is shown in Table 1.

3.2. Study Characteristics. Table 1 presents study characteristic for included 20 cohort studies. These studies were published between 2002 and 2015. The sizes of cases diagnosed as AMD ranged from 181 to 167,838 (total 367,963). The sizes of participants ranged from 860 to $1,445,677$ (total 2,985,316). There were 6 retrospective studies and 14 prospective studies. Three studies were conducted in late AMD only. The mean length of follow-up ranged from 2 to 13.6 years, with a median of 7.7 years. Some studies reported multiple outcomes.

3.3. AMD and Risk of Mortality. Each study and all studies reporting AMD and risk of mortality and cardiovascular disease mortality are shown in Figure 1.

For all-cause mortality, we identified 8 studies of AMD and risk of mortality incidence, involving 32,583 participants. Overall, there was a statistically significant increment of $8 \%$ among AMD patients $(\mathrm{RR}=1.08,95 \% \mathrm{CI}$ : $1.00-1.17$, Figure 1(a)) compared with those of non-AMD patients, and a low heterogeneity was detected $\left(I^{2}=28 \% ; P=0.21\right)$.

For cardiovascular disease mortality we identified 5 studies of AMD and risk of cardiovascular disease mortality incidence, involving 17,250 participants (Table 1). The pooled RR (95\% CI) was $1.18\left(0.98-1.43 ; I^{2}=33.0 \% ; P\right.$ for heterogeneity $=0.20$; Figure $1(\mathrm{~b}))$.

3.4. AMD and Risk of Cardiovascular Events. Each study and all studies reporting AMD and cardiovascular events (CHD, MI, and stroke) are shown in Figure 2.

For CHD risk, we identified 3 studies of AMD and risk of CHD incidence, involving 18,353 participants (Table 1). Again, the pooled RR (95\% CI) was 1.17 (0.94-1.45; $I^{2}=35 \%$; $P$ for heterogeneity $=0.21$; Figure $2(\mathrm{a}))$. And we identified 4 studies of AMD and risk of MI incidence, and high heterogeneity was detected $\left(I^{2}=95 \% ; P<0.0001\right)$. Due to the statistically undetectable heterogeneity, meta-analysis for the MI was cancelled and a descriptive review was conducted instead. One study [18] reported a positive association (i.e., $\mathrm{RR}>1.00)$, two studies $[6,21]$ reported $\mathrm{RR}<1.00$, which was not statistically significant and one study [26] reported a negative association (i.e., $\mathrm{RR}<1.00$ ).

For stroke risk, we identified 8 studies of AMD and risk of stroke incidence, involving 1,424,573 participants (Table 1). Four studies reported a positive association (i.e., RR > 1.00), three studies reported $R R<1.00$ but this was not statistically significant and one study reported $R R<1.00$ and it was statistically significant. High heterogeneity was detected $\left(I^{2}=\right.$ $92 \% ; P<0.00001)$, and the RR (95\% CI) from the randomeffects model was 1.13 (0.93-1.36; Figure 2(b)).

3.5. Subgroup and Sensitivity Analyses. Sensitivity analyses were conducted to explore potential sources of heterogeneity in the association between AMD and stroke. Further analyses investigating the influence of a single study on the overall risk estimate by omitting any of the studies in each turn 


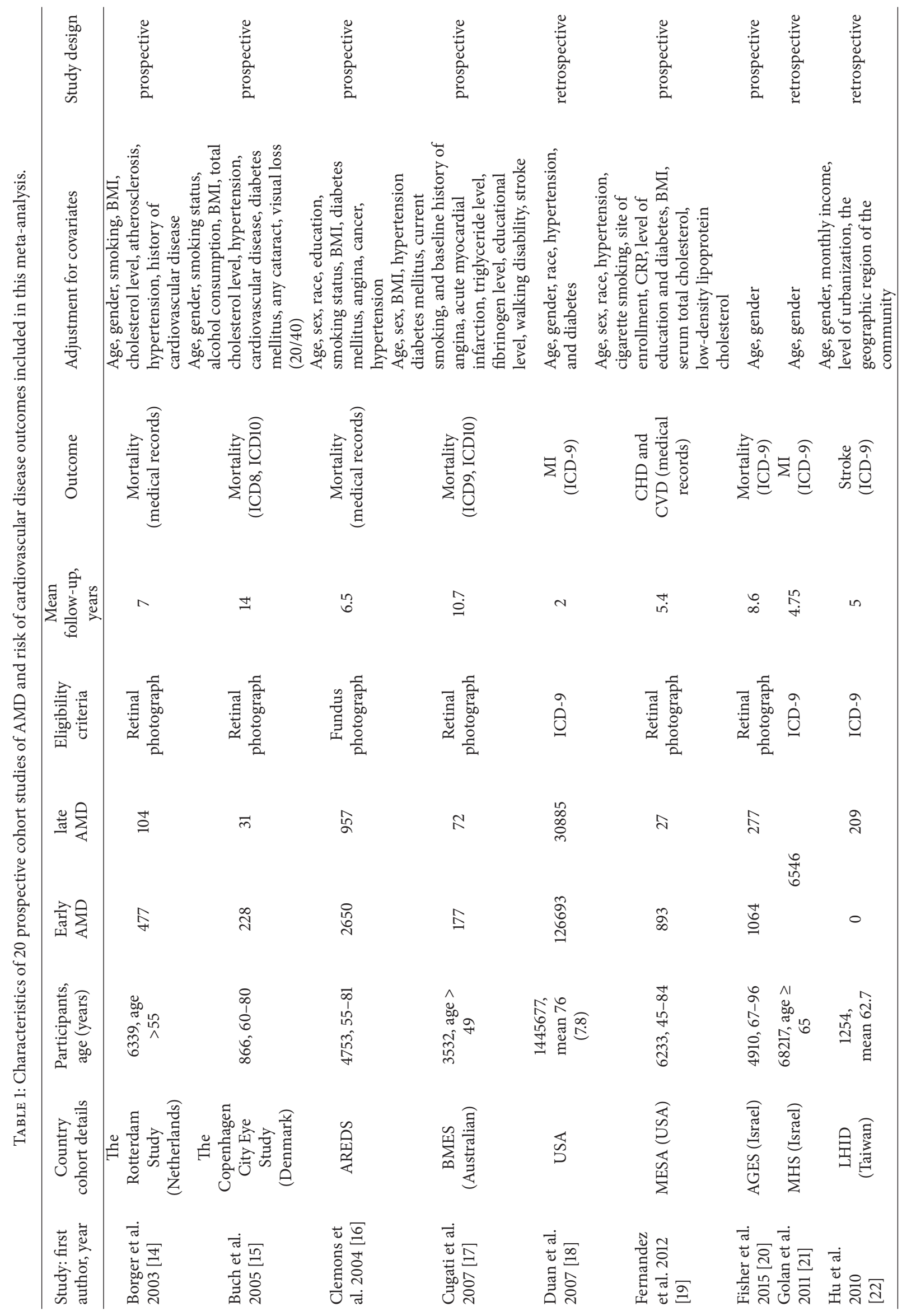




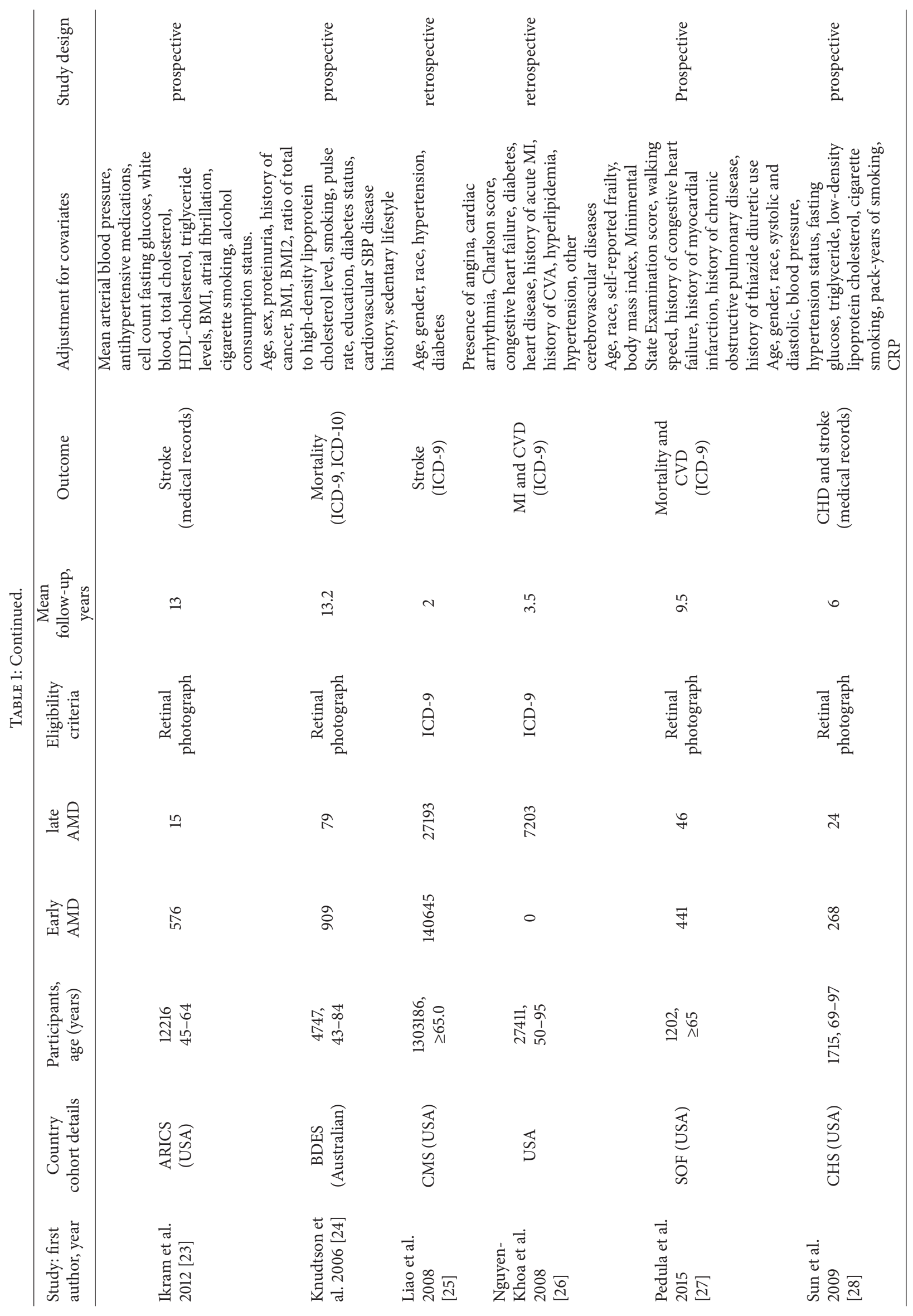




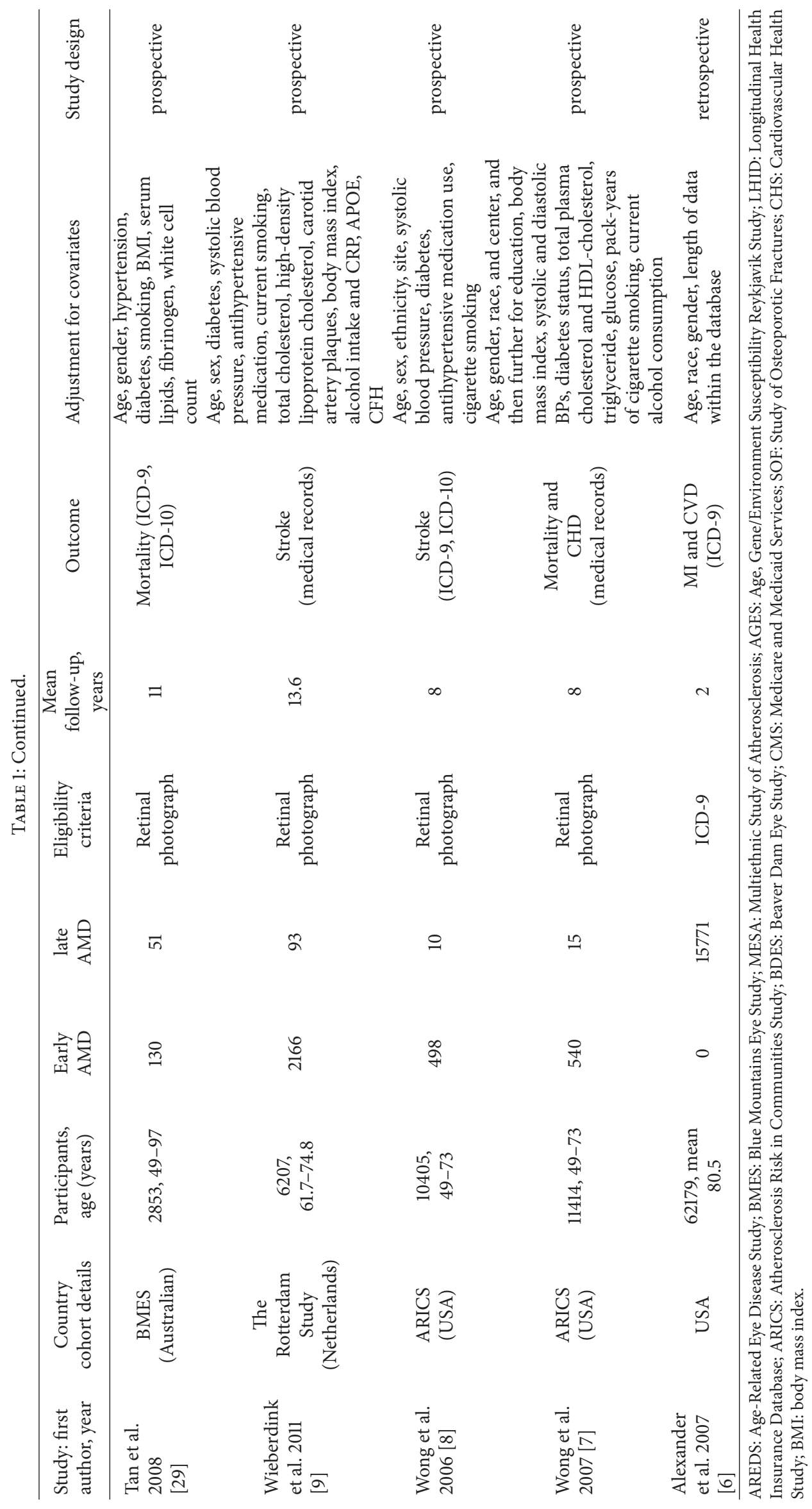




\begin{tabular}{|c|c|c|c|c|c|c|c|c|}
\hline \multirow{2}{*}{$\frac{\text { Study or subgroup }}{\text { Borger et al. } 2003}$} & \multirow{2}{*}{$\frac{\log [\text { risk ratio] }}{-0.0408}$} & \multirow{2}{*}{$\begin{array}{c}\text { SE } \\
0.1397\end{array}$} & \multirow{2}{*}{$\begin{array}{c}\text { Weight } \\
7.6 \%\end{array}$} & \multirow{2}{*}{$\begin{array}{c}\text { Risk ratio } \\
\text { IV, random, 95\% CI } \\
0.96[0.73,1.26]\end{array}$} & \multicolumn{4}{|c|}{$\begin{array}{c}\text { Risk ratio } \\
\text { IV, random, 95\% CI }\end{array}$} \\
\hline & & & & & & & 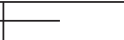 & \\
\hline Buch et al. 2005 & 0.207 & 0.0905 & $14.7 \%$ & $1.23[1.03,1.47]$ & & & $\square$ & \\
\hline Clemons et al. 2004 & 0.1655 & 0.116 & $10.2 \%$ & $1.18[0.94,1.48]$ & & & & \\
\hline Cugati et al. 2007 & 0.1044 & 0.1362 & $7.9 \%$ & $1.11[0.85,1.45]$ & & & & \\
\hline Fisher et al. 2015 & 0.2311 & 0.1179 & $10.0 \%$ & $1.26[1.00,1.59]$ & & & & \\
\hline Knudtson et al. 2006 & -0.0305 & 0.0555 & $25.7 \%$ & $0.97[0.87,1.08]$ & & & - & \\
\hline Pedula et al. 2015 & 0.0953 & 0.0857 & $15.8 \%$ & $1.10[0.93,1.30]$ & & & $=$ & \\
\hline Wong et al. 2007 & -0.0513 & 0.1344 & $8.1 \%$ & $0.95[0.73,1.24]$ & & & & \\
\hline \multicolumn{3}{|l|}{ Total (95\% CI) } & $100.0 \%$ & $1.08[1.00,1.17]$ & & & & \\
\hline \multicolumn{5}{|c|}{ Heterogeneity: $\tau^{2}=0.00 ; \chi^{2}=9.69, \mathrm{df}=7(P=0.21) ; I^{2}=28 \%$} & $\Gamma$ & 1 & 1 & \\
\hline \multicolumn{5}{|c|}{ Test for overall effect: $Z=1.88(P=0.06)$} & 0.5 & 0.7 & 1.5 & 2 \\
\hline
\end{tabular}

(a)

\begin{tabular}{|c|c|c|c|c|c|c|}
\hline \multirow{2}{*}{$\begin{array}{l}\text { Study or subgroup } \\
\text { Clemons et al. } 2004\end{array}$} & \multirow{2}{*}{$\frac{\log [\text { risk ratio] }}{0.4511}$} & \multirow{2}{*}{$\begin{array}{c}\text { SE } \\
0.2151\end{array}$} & \multirow{2}{*}{$\begin{array}{c}\text { Weight } \\
15.3 \%\end{array}$} & \multirow{2}{*}{$\begin{array}{c}\text { Risk ratio } \\
\text { IV, random, 95\% CI } \\
1.57[1.03,2.39]\end{array}$} & \multicolumn{2}{|c|}{$\begin{array}{c}\text { Risk ratio } \\
\text { IV, random, 95\% CI }\end{array}$} \\
\hline & & & & & & $\square$ \\
\hline Cugati et al. 2007 & -0.2877 & 0.2277 & $14.1 \%$ & $0.75[0.48,1.17]$ & & - \\
\hline Fisher et al. 2015 & 0.2311 & 0.1179 & $32.2 \%$ & $1.26[1.00,1.59]$ & & - \\
\hline Pedula et al. 2015 & 0.1655 & 0.1439 & $26.2 \%$ & $1.18[0.89,1.56]$ & & $=$ \\
\hline Tan et al. 2008 & 0.174 & 0.2493 & $12.2 \%$ & $1.19[0.73,1.94]$ & & \\
\hline \multicolumn{3}{|l|}{ Total (95\% CI) } & $100.0 \%$ & $1.18[0.98,1.43]$ & & \\
\hline \multicolumn{5}{|c|}{ Heterogeneity: $\tau^{2}=0.02 ; \chi^{2}=6.01, \mathrm{df}=4(P=0.20) ; I^{2}=33 \%$} & 1 & 1 \\
\hline \multicolumn{5}{|c|}{ Test for overall effect: $Z=1.72(P=0.09)$} & 0.5 & 1.5 \\
\hline
\end{tabular}

(b)

FIGURE 1: (a) Adjusted relative risks of all-cause mortality associated with AMD. (b) RR of cardiovascular disease mortality associated with AMD.

suggested the overall risk estimates were not substantially modified by any single study, with a range from 1.06 (95\% CI: $0.87-1.29$ ) to 1.15 (95\% CI: $0.93-1.44)$. In addition, no single study substantially contributed to the heterogeneity across studies.

We conducted subgroup analyses by length of followup $(<5$ versus $\geq 5)$, number of participants $(<10000$ versus $\geq 10000$ ), type, and study design (Table 2). Exploration of the effect by the type of AMD (early AMD/late AMD) suggested significant association between early AMD and risk of stroke (RR: 1.21, [95\% CI: 1.03 to 1.42]; $P=0.007$ ). The subgroup analysis by study design (i.e., prospective versus retrospective) and number of participants $(<10000$ versus $\geq 10000$ ) did not suggest apparent difference.

\section{Discussion}

In the meta-analysis of 20 population-based cohort studies, our findings show that AMD is associated with around $8 \%$ increased risk of all-cause mortality. From the clinical view point, these values may be considerable. There was no evidence of between-study heterogeneity. We did not find a significant relationship between AMD and incident of cardiovascular events (CHD and stroke) and cardiovascular disease mortality, when data from both prospective and retrospective cohort studies were summarized. But heterogeneity between studies was high.
AMD is a chronic disorder and the major cause of permanent visual impairment among elderly people $[1,2]$. Our meta-analysis of a significant trend of increased allcause mortality with AMD suggests that AMD (early or late AMD) may reflect the status of systemic processes associated with biological aging, being a marker of underlying serious somatic factors or diseases, which could be associated with increased biological aging and decreased survival [4]. However, the precise mechanism of this relationship is unclear. Several plausible mechanisms for the relationship between AMD and mortality were shared common risk factors. It is possible that $\mathrm{AMD}$ accelerates the aging process through poorer vision and greater frailty, leading to more accidents, falls, and fractures, all of which have been linked to higher mortality [30, 31].

Several pathogenic mechanisms for the observed relationship of AMD with CVD have been proposed $[1,2]$. Chronic inflammation is a plausible biologic mechanism for both AMD and CVD [4]. However, our meta-analysis is to show no association of AMD with MI incidence, stroke, and $\mathrm{CHD}$ events and cardiovascular disease mortality. The nonsignificant association between AMD and cardiovascular events and cardiovascular disease mortality may arise from several sources. Inconsistencies between studies might have arisen from the undocumented use of antiangiogenic therapy for the treatment of neovascularization in late AMD. Since the first antivascular endothelial growth factor (anti-VEGF) 


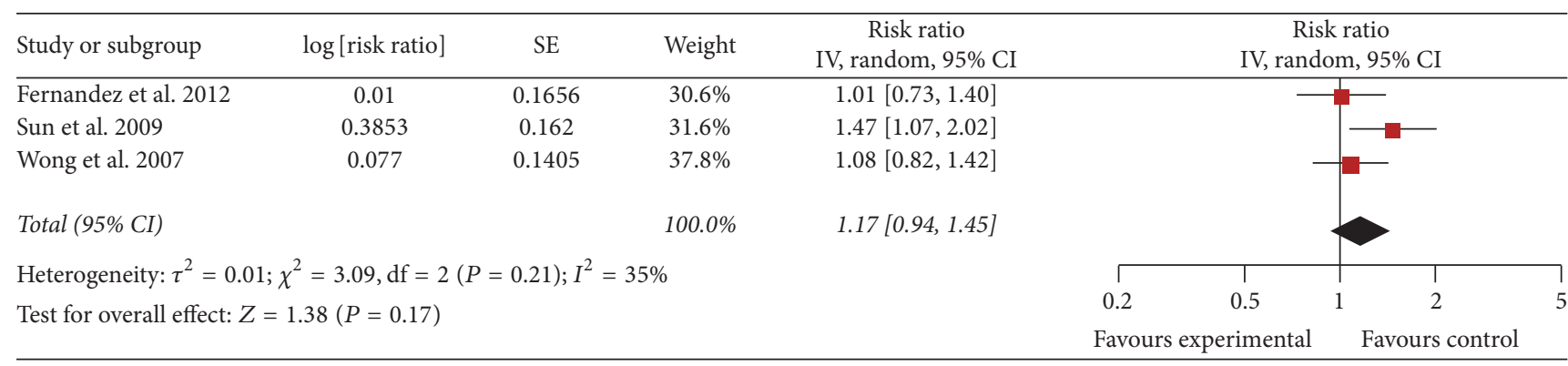

(a)

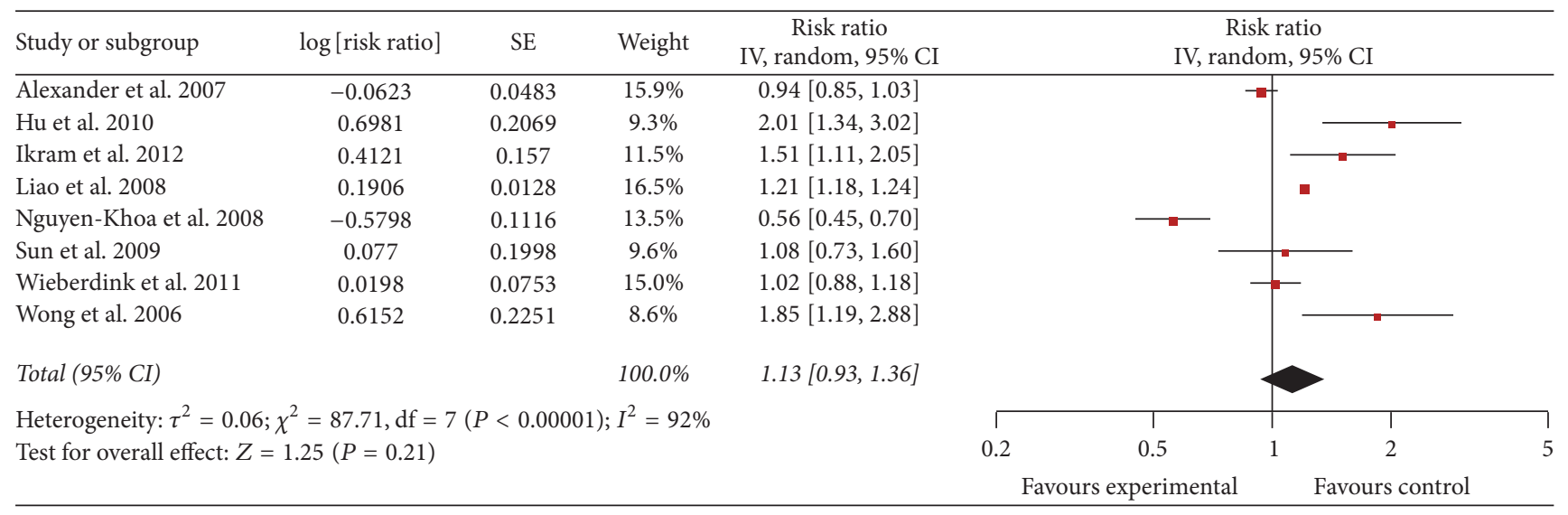

(b)

FIgURE 2: (a) RR of CHD associated with AMD. (b) RR of stroke associated with AMD.

medication approved by the US Food and Drug Administration (FDA) for intravitreal use, pegaptanib, in 2006, the safety of anti-VEGF agents has been controversial given the potential for increased risk of atherothrombotic events when these agents are used systemically [32, 33]. Therefore, more studies confirming that a link exists between AMD and cardiovascular events would be needed before such recommendations can be made. In addition, in some of the studies found in our search, there was a lack of clinical validation to confirm the AMD diagnosis and no information about the confounding effect of smoking on the relationship.

For stroke, we observed substantial heterogeneity in those studies. This is not surprising given the variation in study designs and characteristics of populations between studies. Moreover, we found a significant association between early AMD and over 5 years of follow-up subgroup and risk of stroke incidence. High heterogeneity is observed within all subgroups. Our results and previous work on the topic highlighted the paucity of data regarding the predictive value of $\mathrm{AMD}$ in $\mathrm{CHD} / \mathrm{CVD}$ events and likely reflect the heterogeneity in the study design, length of follow-up, and accuracy of the definitions of ocular and CVD outcomes used in the few studies addressing this clinical question. These differences may explain the discordance of results across studies. The assessment of differences in the prevalence of AMD among ethnicities likely requires a larger number of patients with sufficient power.

Several limitations should be acknowledged as well. First, significant heterogeneity was observed across studies for some outcomes, which may arise from differences in participants' characteristics, study designs, mean follow-up years, sample sizes, and analysis strategies. So we performed subgroup analyses on potential confounders. But moderateto-high heterogeneities still remained in many subgroups. Second, our meta-analysis was limited to published reports. The literature screening and data extraction were conducted independently by two reviewers, and, thus, selection bias was unlikely. Third, the definition of AMD varied across studies. Among some studies, information on CVD was obtained by self-reporting from study participants. In addition, the associations were presented in different forms (OR, HR, $\mathrm{RR}$, etc.), and RR was used as the common measure of association in this meta-analysis. The summary results might be influenced by the conversion of other measures into RR, but such influence, if any, is likely to be small because only a few studies reported ORs. Last, this study includes those inherent in retrospective database studies. The claims data lacks important health-related information such as height, weight, and smoking history. Despite strong associations, residual confounding is still possible given that many studies did not adjust lifestyle factors (e.g., smoking, unhealthy diet, and exercise) in their models.

\section{Conclusions}

Findings from this systematic review support that AMD is associated with increased risk of all-cause mortality. The evidence that AMD predicts incident CVD events or CVD 


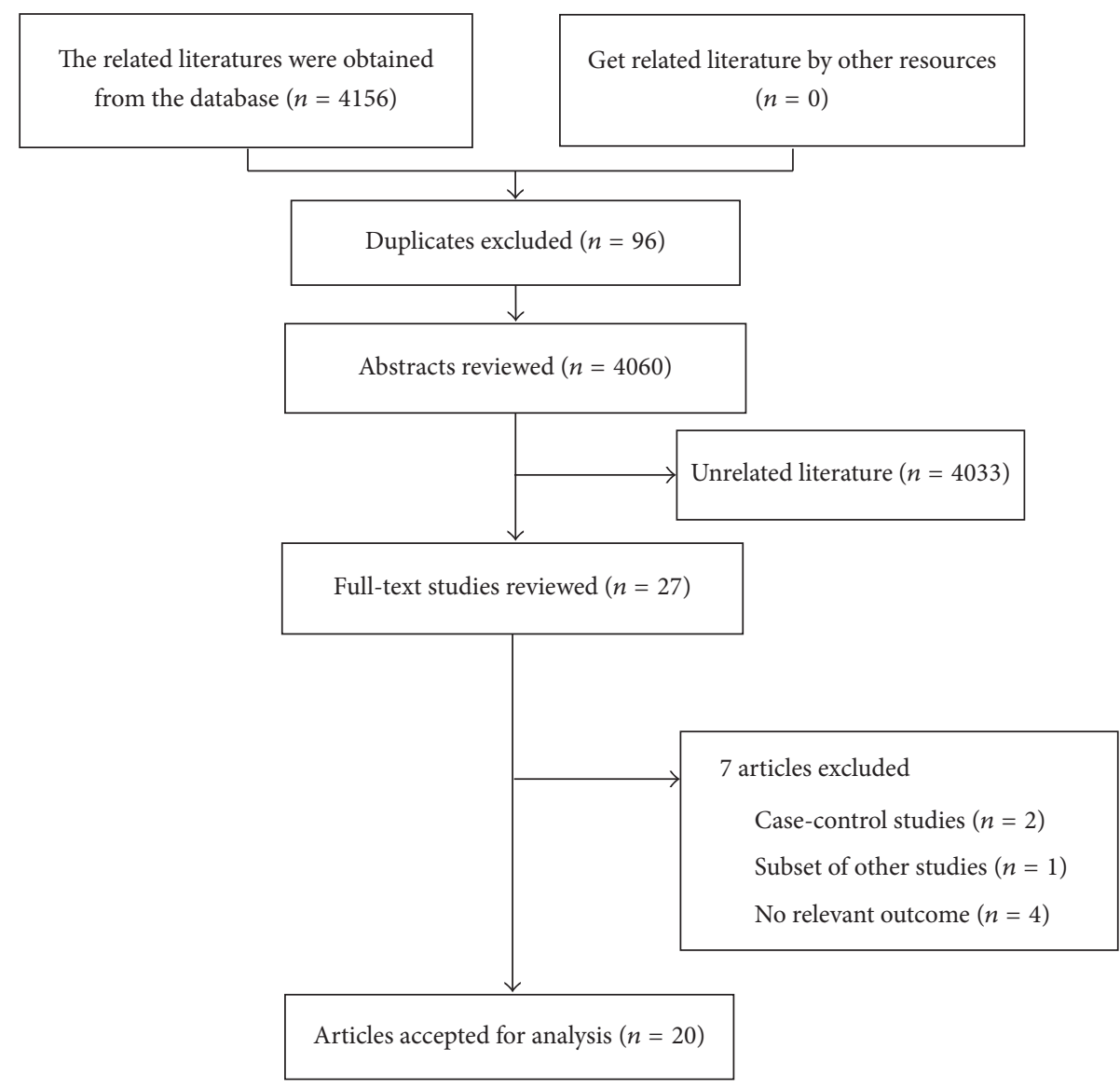

Figure 3: Flow chart of the meta-analysis of AMD and CVD.

TABLE 2: Stratified analyses of stroke associated with AMD.

\begin{tabular}{|c|c|c|c|c|}
\hline Group & Number of studies & RR (95\% CI) & $P$ (heterogeneity) & $I^{2}(\%)$ \\
\hline Total & 8 & $1.13[0.93,1.36]$ & $<0.00001$ & 92 \\
\hline \multicolumn{5}{|c|}{ Length of follow-up (years) } \\
\hline$<5$ & 3 & $0.88[0.64,1.20]$ & $<0.00001$ & 97 \\
\hline$\geq 5$ & 5 & $1.40[1.05,1.87]$ & 0.002 & 76 \\
\hline \multicolumn{5}{|c|}{ Number of participants } \\
\hline$<10000$ & 3 & $1.27[0.86,1.87]$ & 0.009 & 79 \\
\hline$\geq 10000$ & 5 & $1.07[0.83,1.38]$ & $<0.00001$ & 95 \\
\hline \multicolumn{5}{|l|}{ Type } \\
\hline Early AMD & 5 & $1.21[1.03,1.42]$ & 0.007 & 71 \\
\hline Late AMD & 6 & $1.14[0.85,1.52]$ & $<0.00001$ & 95 \\
\hline \multicolumn{5}{|l|}{ Study design } \\
\hline Prospective & 4 & $1.07[0.90,1.26]$ & 0.03 & 66 \\
\hline Retrospective & 4 & $1.22[0.75,1.99]$ & $<0.00001$ & 95 \\
\hline
\end{tabular}

mortality remains inclusive and warrants further study in the future.

\section{Disclosure}

The funders of the project were not involved in study design; in the collection; in the data analysis; or in the writing of the report and publication.

\section{Competing Interests}

Authors decalre no competing interests.

\section{Authors' Contributions}

Jie Wang and Yangjing Xue contributed equally to this work. 


\section{Acknowledgments}

The authors acknowledge the Second Affiliated Hospital, Wenzhou Medical University, for supporting the work of their study.

\section{References}

[1] D. Pascolini, S. P. Mariotti, G. P. Pokharel et al., "2002 Global update of available data on visual impairment: a compilation of population-based prevalence studies," Ophthalmic Epidemiology, vol. 11, no. 2, pp. 67-115, 2004.

[2] N. Congdon, B. O’Colmain, C. C. Klaver et al., "Causes and prevalence of visual impairment among adults in the United States," Archives of ophthalmology, vol. 122, no. 4, pp. 477-485, 2004.

[3] R. D. Jager, W. F. Mieler, and J. W. Miller, "Age-related macular degeneration," New England Journal of Medicine, vol. 358, no. 24, pp. 2606-2617, 2008.

[4] J. Z. Nowak, "Age-related macular degeneration (AMD): pathogenesis and therapy," Pharmacological Reports, vol. 58, no. 3, pp. 353-363, 2006.

[5] R. Klein, T. Peto, A. Bird, and M. R. Vannewkirk, "The epidemiology of age-related macular degeneration," American Journal of Ophthalmology, vol. 137, no. 3, pp. 486-495, 2004.

[6] S. L. Alexander, W. T. Linde-Zwirble, W. Werther et al., "Annual rates of arterial thromboembolic events in medicare neovascular age-related macular degeneration patients," Ophthalmology, vol. 114, no. 12, pp. 2174-2178, 2007.

[7] T. Y. Wong, G. Tikellis, C. Sun, R. Klein, D. J. Couper, and A. R. Sharrett, "Age-related macular degeneration and risk of coronary heart disease: the Atherosclerosis Risk in Communities Study," Ophthalmology, vol. 114, no. 1, pp. 86-91, 2007.

[8] T. Y. Wong, R. Klein, C. Sun et al., "Age-related macular degeneration and risk for stroke," Annals of Internal Medicine, vol. 145, no. 2, pp. 98-106, 2006.

[9] R. G. Wieberdink, L. Ho, M. K. Ikram et al., "Age-related macular degeneration and the risk of stroke: The Rotterdam Study," Stroke, vol. 42, no. 8, pp. 2138-2142, 2011.

[10] J. Wu, M. Uchino, S. M. Sastry, and D. A. Schaumberg, "Agerelated macular degeneration and the incidence of cardiovascular disease: a systematic review and meta-analysis," PLOS ONE, vol. 9, no. 3, Article ID e89600, 2014.

[11] L. A. Stewart, M. Clarke, M. Rovers et al., "Preferred reporting items for systematic review and meta-analyses of individual," The Journal of the American Medical Association, vol. 313, no. 16, pp. 1657-1665, 2015.

[12] J. Zhang and K. F. Yu, "What's the relative risk? A method of correcting the odds ratio in cohort studies of common outcomes," The Journal of the American Medical Association, vol. 280, no. 19, pp. 1690-1691, 1998.

[13] R. DerSimonian and N. Laird, "Meta-analysis in clinical trials revisited," Contemporary Clinical Trials, vol. 45, pp. 139-145, 2015.

[14] P. H. Borger, R. van Leeuwen, C. A. A. Hulsman et al., "Is there a direct association between age-related eye diseases and mortality? The Rotterdam Study," Ophthalmology, vol. 110, no. 7, pp. 1292-1296, 2003.

[15] H. Buch, T. Vinding, M. La Cour, G. B. Jensen, J. U. Prause, and N. V. Nielsen, "Age-related maculopathy: a risk indicator for poorer survival in women: The Copenhagen City Eye Study," Ophthalmology, vol. 112, no. 2, pp. 305-312, 2005.
[16] T. E. Clemons, N. Kurinij, R. D. Sperduto, and AREDS Research Group, "Associations of mortality with ocular disorders and an intervention of high-dose antioxidants and zinc in the agerelated eye disease study: AREDS report No. 13," Archives of Ophthalmology, vol. 122, no. 5, pp. 716-726, 2004.

[17] S. Cugati, R. G. Cumming, W. Smith, G. Burlutsky, P. Mitchell, and J. J. Wang, "Visual impairment, age-related macular degeneration, cataract, and long-term mortality: the blue mountains eye study," Archives of Ophthalmology, vol. 125, no. 7, pp. 917924, 2007.

[18] Y. Duan, J. Mo, R. Klein et al., "Age-related macular degeneration is associated with incident myocardial infarction among elderly Americans," Ophthalmology, vol. 114, no. 4, pp. 732-737, 2007.

[19] A. B. Fernandez, T. Y. Wong, R. Klein et al., "Age-related macular degeneration and incident cardiovascular disease: the Multi-Ethnic study of atherosclerosis," Ophthalmology, vol. 119, no. 4, pp. 765-770, 2012.

[20] D. E. Fisher, F. Jonasson, G. Eiriksdottir et al., "Age-related macular degeneration and mortality in community-dwelling elders: the age, gene/environment susceptibility reykjavik study," Ophthalmology, vol. 122, no. 2, pp. 382-390, 2015.

[21] S. Golan, V. Shalev, M. Goldstein, G. Treister, G. Chodick, and A. Loewenstein, "The rate of myocardial infarction events among patients with age-related macular degeneration: a population-based study," Graefe's Archive for Clinical and Experimental Ophthalmology, vol. 249, no. 2, pp. 179-182, 2011.

[22] C.-C. Hu, J.-D. Ho, and H.-C. Lin, "Neovascular age-related macular degeneration and the risk of stroke: a 5-year population-based follow-up study," Stroke, vol. 41, no. 4, pp. 613-617, 2010.

[23] M. K. Ikram, P. Mitchell, R. Klein, A. R. Sharrett, D. J. Couper, and T. Y. Wong, "Age-related macular degeneration and longterm risk of stroke subtypes," Stroke, vol. 43, no. 6, pp. 1681-1683, 2012.

[24] M. D. Knudtson, B. E. K. Klein, and R. Klein, "Age-related eye disease, visual impairment, and survival: the beaver dam eye study," Archives of Ophthalmology, vol. 124, no. 2, pp. 243-249, 2006.

[25] D. Liao, J. Mo, Y. Duan et al., "Is age-related macular degeneration associated with stroke among elderly Americans?" The Open Ophthalmology Journal, vol. 2, no. 1, pp. 37-42, 2008.

[26] B.-A. Nguyen-Khoa, E. L. Goehring Jr., W. Werther, E. W. Gower, D. V. Do, and J. K. Jones, "Hospitalized cardiovascular diseases in neovascular age-related macular degeneration," Archives of Ophthalmology, vol. 126, no. 9, pp. 1280-1286, 2008.

[27] K. L. Pedula, A. L. Coleman, F. Yu et al., "Age-related macular degeneration and mortality in older women: the study of osteoporotic fractures," Journal of the American Geriatrics Society, vol. 63, no. 5, pp. 910-917, 2015.

[28] C. Sun, R. Klein, and T. Y. Wong, "Age-related macular degeneration and risk of coronary heart disease and stroke: The Cardiovascular Health Study," Ophthalmology, vol. 116, no. 10, pp. 1913-1919, 2009.

[29] J. S. L. Tan, J. J. Wang, G. Liew, E. Rochtchina, and P. Mitchell, "Age-related macular degeneration and mortality from cardiovascular disease or stroke," The British Journal of Ophthalmology, vol. 92, no. 4, pp. 509-512, 2008.

[30] R. Chou, T. Dana, and C. Bougatsos, "Screening older adults for impaired visual acuity: a review of the evidence for the U.S. Preventive Services Task Force," Annals of Internal Medicine, vol. 151, no. 1, pp. 44-58, 2009. 
[31] J. Kulmala, P. Era, O. Pärssinen et al., "Lowered vision as a risk factor for injurious accidents in older people," Aging Clinical and Experimental Research, vol. 20, no. 1, pp. 25-30, 2008.

[32] F. G. Holz, S. Schmitz-Valckenberg, and M. Fleckenstein, "Recent developments in the treatment of age-related macular degeneration," The Journal of Clinical Investigation, vol. 124, no. 4, pp. 1430-1438, 2014.

[33] S. D. Solomon, K. Lindsley, S. S. Vedula, M. G. Krzystolik, and B. S. Hawkins, "Anti-vascular endothelial growth factor for neovascular age-related macular degeneration," The Cochrane Database of Systematic Reviews, vol. 8, Article ID CD005139, 2014. 


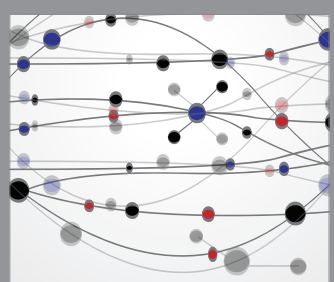

The Scientific World Journal
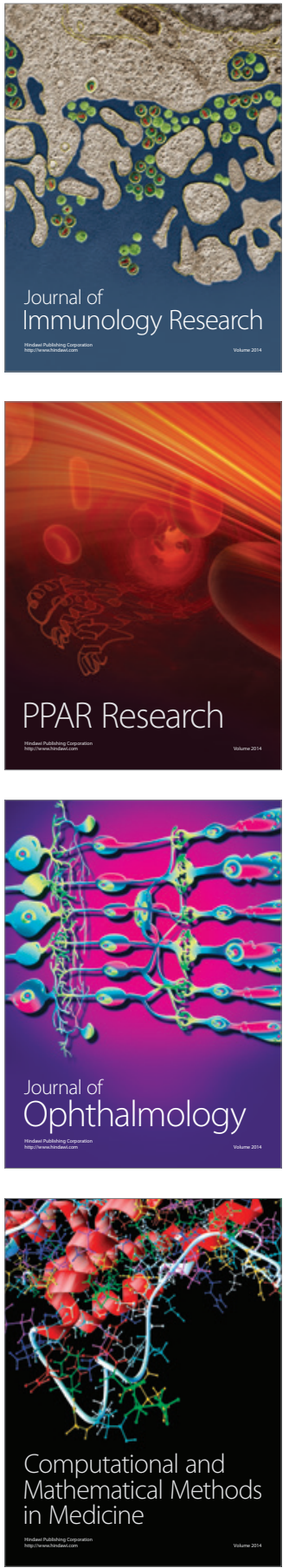

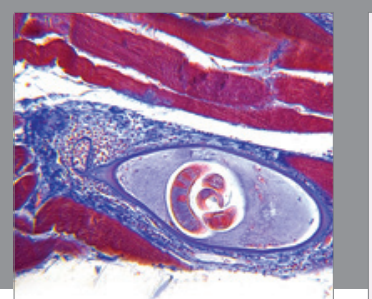

Gastroenterology Research and Practice

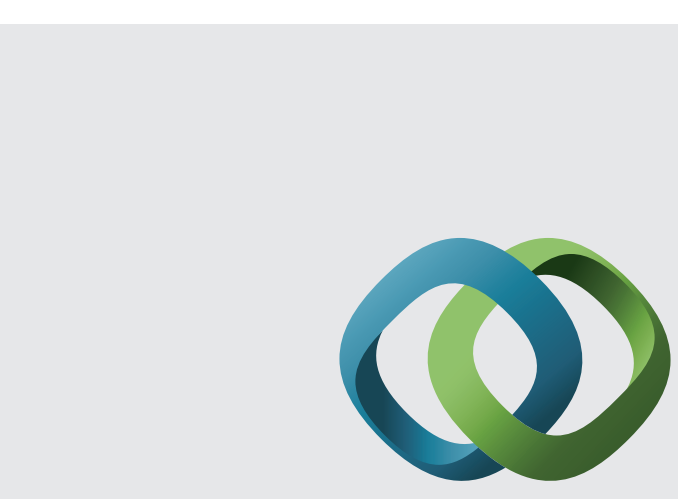

\section{Hindawi}

Submit your manuscripts at

http://www.hindawi.com
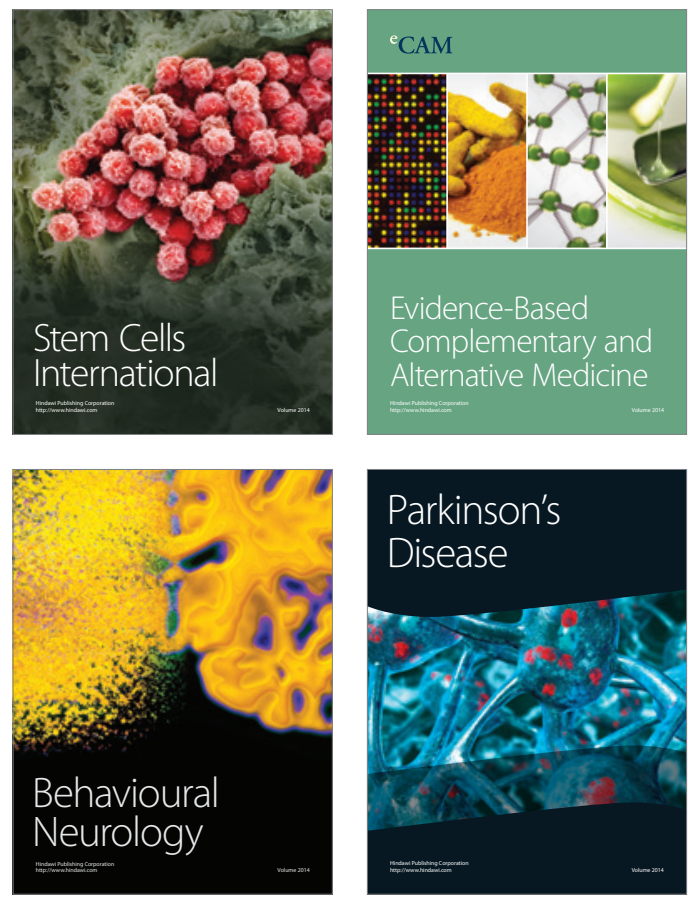
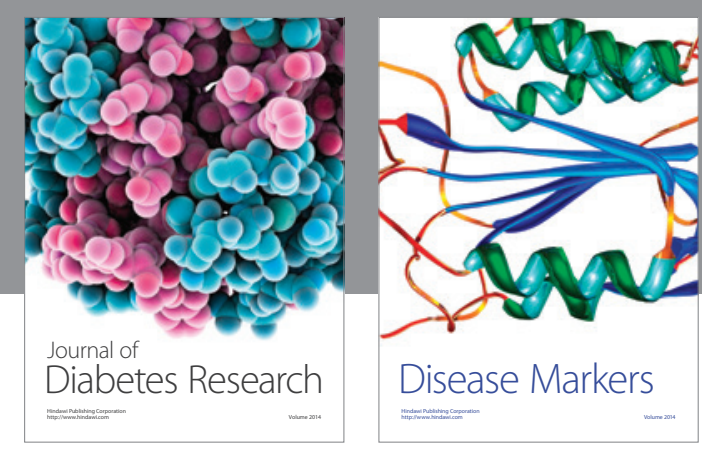

Disease Markers
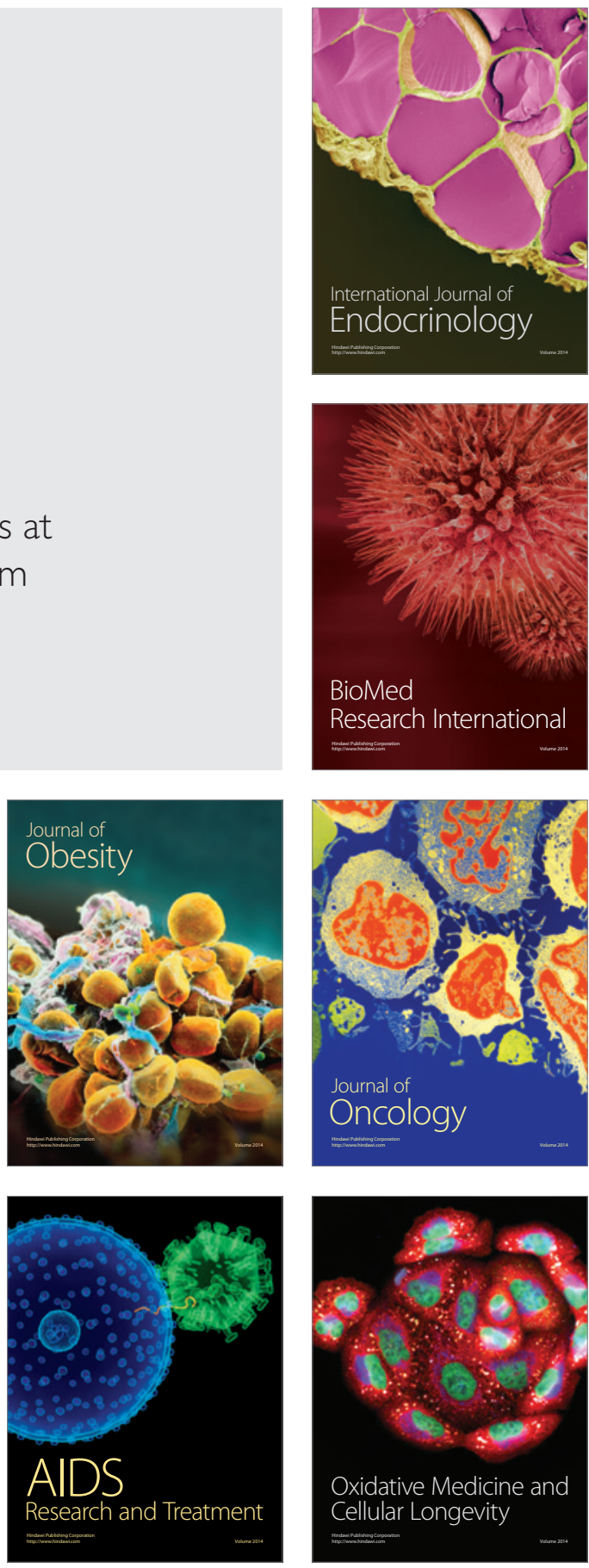